\title{
Bolívar y Chávez. Fundamentos históricos y religiosos del populismo chavista
}

\author{
Bolívar y Chávez. Historical and Religious Foundations of Chavez's \\ Populism
}

Javier Rodríguez Martínez

UNED

\section{RESUMEN}

Desde hace más de dos décadas, la política venezolana ha estado marcada por la presencia del chavismo como orientación revolucionaria del país. Independientemente de que hoy en día esa política es reconocida como una política fracasada que ha provocado el éxodo de millones de venezolanos, esa política estuvo dirigida en sus primeros a la transformación política, social y económica de la nación en pos del llamado socialismo del siglo XXI. Precisamente es en este primer período en el que nos vamos a concentrar. Si definimos el populismo en sentido estricto como esa forma de política de masas que parte de la idea de la existencia de una voluntad popular y la existencia de un modo carismático de dominación basado en la vinculación directa del líder con las masas, el chavismo fue un fenómeno populista. En el presente artículo muestro, basándome en escritos biográficos, entrevistas y discursos, la adecuación del caso venezolano a la definición propuesta y los fundamentos religiosos e históricos del mismo.

PALABRAS CLAVE: populismo, chavismo, modo carismático de dominación, religión y política, caudillismo 


\begin{abstract}
For more than two decades, Venezuelan politics has been marked by the presence of Chavismo as the country's revolutionary orientation. Regardless of the fact that nowadays this policy is recognized as a failed policy that has caused the exodus of millions of Venezuelans, this policy was aimed in its first at the political, social and economic transformation of the nation in pursuit of the socalled socialism of the 21st century. It is precisely in this first period that we are going to concentrate. If we define populism in the strict sense as that form of mass politics that starts from the idea of the existence of a popular will and the existence of a charismatic mode of domination based on the direct link between the leader and the masses, Chavismo was a populist phenomenon. In this article I show, based on biographical writings, interviews and speeches, the adequacy of the Venezuelan case to the proposed definition and its religious and historical foundations.
\end{abstract}

KEY WORDS: populism, chavismo, charismatic mode of domination, religion and politics, caudillism

\title{
EL POPULISMO VENEZOLANO
}

El populismo es una forma de política de masas. Sus características son la aspiración de representar y actuar en nombre del pueblo, lo que le distingue de políticas de clases y políticas pluralistas, basadas en alianzas entre diferentes grupos de interés. Ahora bien, el populismo es un concepto difícil de definir, comenzando por la cantidad histórica de populismos habidos y aún existentes hoy de diverso signo. Por esta razón proponemos aquí una definición mínima: la dominación carismática del líder que pretende representar directamente al pueblo y la entrega de éste a las pretensiones del primero. Esta pretensión, para el caso latinoamericano, ha ido acompañada de algunas características agrupables bajo la categoría de sociales, políticas y económicas; así el impulso anti-status quo, la composición multiclasista de los seguidores y las políticas económicas que enfatizan el crecimiento endógeno, la distribución y la estimulación de la demanda. Si a ellas añadimos la situación de grave crisis en la que la sociedad se halla en el momento en que surge el líder y la dicotomía "pueblo/élite" tenemos las condiciones generales y las características exteriores del populismo latino de signo izquierdista. El caso venezolano se va a ajustar a esta definición con algunas características singulares. 
Hawkins ha ensayado con éxito una definición mínima de populismo, realizada sólo en términos políticos. Esta definición se basa en dos elementos: por un lado, la presencia de un modo de vinculación entre los votantes y los políticos y, por otro, la existencia de un discurso democrático basado en la idea de una voluntad popular y de una lucha entre el "pueblo" y la "elite"1.

La presencia del líder implica, en un primer momento, tres cosas: la presencia de una crisis, el reconocimiento de las capacidades carismáticas del líder y la eliminación de estructuras políticas organizativas existentes así como la creación de instituciones políticas débiles. ${ }^{2}$ Todo se refiere al "pueblo", y el pueblo se construye a través de elementos que apelan a su identidad y su memoria, elementos que le hacer ser sujeto y actor. Aquí destacaremos la matriz histórica de la secuencia líder-pueblo-revolución así como los fundamentos religiosos del caso venezolano.

Es en el plano del discurso donde se reflejarán estas características. El discurso demagógico consiste en la apelación más o menos sistemática a lo emocional y en eludir el contenido doctrinal o programático de la acción política. Procedente de un líder al que se le atribuyen poderes extraordinarios, la fuerza del discurso está en relación con la fuerza maligna que ha producido la crisis. Al reducir las causas de unos fenómenos sociales a una sola causa y personalizarla en un grupo o elite social, la capacidad mesiánica se concentra también en un gran hombre. La crisis y el héroe que surge de ella están en relación directa en cuanto a su tamaño. La lucha del héroe contra la fuerza que llevó al país a la crisis se manifiesta en el carácter típicamente maniqueo del líder populista.

\section{EL “PUEBLO”}

Ya desde las revoluciones liberales, "el pueblo" - como señala Álvarez Junco "es una referencia mítica opuesta a la del rey que se vería ungido con atributos sacros dignos de este papel". Para el abate Lammenais "el pueblo (...) es dios." Michelet fue, continua Álvarez Junco, quien en Le Peuple explicaría el fundamento de la nueva verdad social. El pueblo lleva en sus profundidades el

${ }^{1}$ Cifr. K. Hawkins, "Populism in Venezuela: the Rise of Chavismo", Third World Quaterly, vol. 24, oㅡ 6, 2003, pp. 1137-1160, p. 1138.

${ }^{2}$ Cifr. K. Hawkins, op. cit., idem. 
"calor de lo social", el "tesoro de la vida universal" y las "fuentes agotadas del amor". 3

La privación es la inocencia del pueblo, su virtud. Su lucha como "depositario de la virtud" define al otro, el "maligno." Por un lado, pobreza y corrupción se enfrentan en la acción política (pueblo-pobreza o los excluidos) y el bien y el mal en un nivel inferior: "Aquí huele a azufre". El enemigo del pueblo está en conspiración perpetua, se despliega en la forma de un enjambre de espíritus malignos. "La teoría conspirativa", señala Kenneth Minogue, "es a la política lo que el animismo a la ciencia: la creencia en que todo está determinado por espíritus." ${ }^{5}$ Sometidos a una fuerte ansiedad por el curso de los acontecimientos, los miembros de un movimiento oscilan entre sentimientos de impotencia y de imbatibilidad. De ahí la función tonificante del líder cuando les ofrece victoria tras victoria o cuando se muestra fuerte. No basta que el líder sea un hombre con carisma, en las sociedades modernas, el carisma se ejerce desde el discurso: el "carisma del discurso". Este discurso tiene en la superficie una coloración redentorista y una obsesión maniquea. El discurso opera, yendo más en profundidad, en dos ámbitos: en el de la identidad colectiva: recentramiento social, y otra movilizadora.

Siguiendo a Edward Shils, "el populismo implica la adhesión a dos principios cardinales: a) la supremacía de la voluntad del pueblo, identificándole con la justicia y la moralidad; b) la relación directa entre el pueblo y sus líderes."' Pero ambos principios se logran mediante la intervención de un líder carismático, una persona con el don de liderar a las masas y, sobre todo, con un discurso que apelando a lo emocional logre hacer sentir al pueblo su constitución en una unidad, en una entidad con identidad y memoria colectiva. El "carisma del discurso" es pues el que vincula directamente al líder con el pueblo. En el carisma hay dos polos, uno relativo al recentramiento de los social y otro dirigido a la acción revolucionaria.

\footnotetext{
${ }^{3}$ Los entrecomillados en J. Álvarez Junco, (comp.), Populismo, caudillaje y discurso demagógico, C.I.S., Madrid, 1987, p. 251.

${ }^{4}$ S. Torres Ballesteros, "El populismo. Un concepto escurridizo", en J. Álvarez Junco, (comp.), Populismo, caudillaje y discurso demagógico, C.I.S., Madrid, 1987, pp.172173.

${ }^{5}$ Cif. Kenneth Minogue, "El populismo como movimiento político", en Ionnescu y Gellner, (comp.), Populismo, Amorrortu, Buenos Aires, p. 253.

${ }^{6}$ Citado en P. Worsley en Populismo, Amorrortu, Buenos Aires, 1970, p.298.
} 


\section{HISTORIA DEL CHAVISMO}

Desde la revolución cubana de hace medio siglo no ha habido en América Latina un proceso político que haya concitado el interés de la opinión pública internacional más extraordinario e insólito que la Revolución Bolivariana liderada por el ex teniente coronel Hugo Chávez Frías. Tanto es así que los encuentros entre Castro y Chávez dieron la sensación de ser desde ciertos puntos de vista un ritual sucesorio. La temprana muerte del comandante y su sustitución por un líder sin carisma truncaron esta visión histórica.

Nadie escribió sobre Venezuela en el último tercio del siglo XX. Tenía una democracia partitocrática que excluía a dos tercios de la población y una clase media que estaba convencida de soñar el sueño americano. Hasta que en 1989 se produjo el primer "sacudón" con el llamado "caracazo", unos días de saqueos, coincidentes al inicio con una huelga de policías, que surgieron en Caracas como consecuencia de un aumento brusco de los precios de la gasolina, y que se fue extendiendo a otras ciudades, entre otras cosas, por su divulgación en televisión. En 1992 se produjo la asonada en la que participaría Hugo Chávez y de la que él, en una impactante intervención en la televisión, se hizo responsable. Fue su inicio hasta la victoria electoral de 1998 con el segundo apoyo electoral más elevado de la historia de la democracia venezolana.

\section{LA CRISIS ECONÓMICA Y POLÍTICA}

En la década de 1930 Uslar Pietri popularizó la tesis de que el Estado se descapitalizaba al exportar petróleo, por lo que era necesario invertir esos ingresos: "sembrar el petróleo". Úslar Pietri sintetiza el dilema nacional planteado entre la hormiga ahorradora, que maneja el ciclo de la siembra y la cosecha con sabiduría campesina, y la cigarra gastadora que vive un presente eterno como si el petróleo no tuviese precios volátiles o fuese a durar eternamente. Entre 1974 -cuando se nacionalizan las instalaciones petrolíferas foráneas- y 1984, cuando ocurre la macrodevaluación, el "viernes negro", Venezuela atraviesa su periodo llamado saudita. Las compañías extractoras y

\footnotetext{
7 "Si hubiéramos de proponer una divisa para nuestra política económica lanzaríamos la siguiente, que me parece resumir dramáticamente esa necesidad de invertir la riqueza producida por el sistema destructivo de la mina, en crear riqueza agrícola, reproductiva y progresiva: sembrar el petróleo. (A. Úslar Pietri, Sembrar el petróleo, Diario Aurora, 14 de julio de 1936. El texto en:

www.analitica.com/bitblioteca/uslar/sembrar_el_petroleo.asp).
} 
refinadoras abandonaron el país movidas por el rigor fiscal y el Estado vio una oportunidad para realizar el viejo sueño venezolano de una industria petrolera propia. Su resultado iba a ser Petróleos de Venezuela S.A. (PDVSA), empresa líder y emblemática, llamada a construir un estado dentro del Estado. Sus rentas se destinaron a grandes proyectos de inversión y creación industrial, combinadas con mejoras salariales generalizadas. La política de sustitución de importaciones, en boga durante los 70 y apoyada por el Banco Interamericano de Desarrollo, parecía capaz de cumplir el viejo lema de Uslar Pietri, lanzando un proyecto irreversible de modernización económica, política y social. Pero se genera una estructura clientelar bipartidista, los "cogollos", y entre la población se extiende la idea de que Venezuela era un país rico pero corrupto8. Esta percepción da lugar a una idea de doble filo, según la posición de clase: la integración en el modo de vida norteamericano para unos, que frecuentan Miami para ir de compras, y la sospecha de que si el petróleo, que es de todos, produce tanta riqueza y no llega nada a mi bolsillo es porque alguien se lo está quedando. Este sentimiento de resentimiento en una sociedad dual se va a ir acumulando.

El Estado como conductor de esa modernización no logra asimilar creativamente -suscitando comercio e industria- en el tejido económico venezolano ese volumen de inversión, a despecho de que las importaciones siguieran creciendo. Se prepara una fuga de capitales y se cuestiona el papel y la eficacia del Estado engordado por la partitocracia y el nepotismo pero incapaz de poner la economía petrolera, que según los precios del crudo puede llegar al 80\% de su presupuesto, al servicio de los intereses del país. El Estado deja de ser percibido como solución y pasa a ser parte del problema, mientras el ejecutivo crea una CONAPRE (Comisión Nacional para la Reforma del Estado) que supone un nuevo gasto improductivo.

Hay ya un claro consenso sobre la necesidad de reformar el Estado y su papel en la modernización económica, pero las redes clientelares y la partitocracia no encuentran otro sustituto que una salva mediática contra el Estado y la burocracia. A finales de los 80 , esta crisis de eficacia es abordada en el marco del Consenso de Washington, entendiéndose que la ineficacia procede del Estado, de su excesiva burocracia, de la partitocracia y de las redes clientelares. Y aquí

\footnotetext{
${ }^{8}$ La idea de que Venezuela es un país rico ha sido tratada por Antonio de Lisio, "La idea de la 'riqueza natural' en Venezuela: de la leyenda de 'El Dorado' a la metáfora de la 'siembra del petróleo', en: Daniel Mato (coord.), Políticas de economía, ambiente y sociedad en tiempos de globalización. Facultad de Ciencias Económicas y Sociales, Universidad Central de Venezuela, Caracas, 2005, pp. 211-232.
} 
comienza la crisis de legitimidad que prepara el terreno para la intervención militar, primero, y carismática después del líder venezolano.

Para acabar con la partitocracia se reforma la elección de gobernadores y alcaldes y se establece que sea por elección directa. Se busca dar más margen al carisma mediático de los líderes que a la organización y esto contribuirá en cierta medida a un tipo de contienda que favorecerá a Hugo Chávez. Y más aún si los líderes de los dos grandes partidos venezolanos, el socialdemócrata $\mathrm{AD}$ y el democristiano COPEI, deciden salirse de sus propios partidos, fundar otros y postularse ellos mismos como los líderes carismáticos destinados a acabar con la partitocracia. En 1989 ganó las elecciones de nuevo Carlos Andrés Pérez, el constructor de la Venezuela saudita. Una vez en La Casona justificó el ajuste económico como una imposición de la oligarquía imperialista, pero instando a la vez a la resignación. Este discurso ambiguo no dio resultado, pues el electorado había votado al político que había prometido llevar a Venezuela a la ilusión de los viejos tiempos, no al que había asumido el programa del FMI, y bastó ponerlo en marcha para que empezasen los problemas sociales. Junto a una liberalización en las tasas de cambio, otras medidas de ajuste fueron eliminar el control de precios para la gasolina, cuyo resultado fue elevar en un 30\% el del transporte urbano y un $85 \%$ el de los combustibles. Poco después ocurre el "caracazo", que Carlos Andrés Pérez reprime con extrema dureza, produciendo muchos desaparecidos.

Aún no se había tomado suficientemente conciencia de hasta qué punto no sólo la prosperidad económica sino la democracia misma dependía de identificar al Estado con algún sistema de distribución de la renta. En 1992 hubo dos asonadas y nuevos actores se lanzaron al escenario político abierto por el "caracazo" buscando explotar el descontento del pueblo. La conmoción intentó resolverse con un chivo expiatorio que fue el propio Carlos Andrés Pérez, acusado de corrupción y expulsado del país, pero la cuestión de fondo seguía intacta. Además de no funcionar, la solución FMI a la crisis de eficacia y legitimidad política daba lugar a nuevas dinámicas, que acabarían siendo incontrolables. Llamativamente, a la expulsión de Pérez sigue un nuevo intento calcado del anterior, esta vez con el veterano político Rafael Caldera al frente, fundador del partido democristiano COPEI, del que también él se desvincularía.

Con Hugo Chávez encarcelado tras su intentona golpista, Rafael Caldera tantea las posibilidades de desmarcarse de la partitocracia para ganar el favor del electorado. Pero pronuncia en el Parlamento un discurso que fue entendido como un mensaje al pueblo, que había apoyado el golpe, de que él comprendía los motivos del mismo. 


\begin{abstract}
En esto momentos debemos darle una respuesta al pueblo y tengo la convicción de que no es la repetición de los mismos discursos que hace treinta años se pronunciaban cada vez que ocurría algún levantamiento (...) El golpe militar es censurable y condenable en toda forma, pero sería ingenuo pensar que se trata solamente de una aventura de unos cuantos ambiciosos (...) Hay un entorno, hay un mar de fondo, hay una situación grave en el país y si esa situación no se enfrenta, el destino nos reserva muchas y muy graves preocupaciones ${ }^{9}$.
\end{abstract}

Comienza así la segunda intentona de relegitimar el tejido político venezolano buscando una regeneración basada en el carisma y una superación de la odiada partitocracia. La estrategia volvió a ser la de un viejo líder político (Caldera tenía 83 años cuando se presentó a su segundo mandato) que se separa de su partido y concurre a las elecciones "desde fuera" del establecimiento político. Tras ganar las elecciones forma un gobierno heterogéneo, en el que destaca la presencia del veterano ex guerrillero Teodoro Petkoff como Ministro de Economía. Petkoff, que devino en conocido opositor de Chávez y director del periódico Tal Cual, será el encargado de negociar el segundo ajuste con el FMI, que esta vez iba a llamarse "Agenda Venezuela", y es entonces cuando Caldera toma, para ganarse el favor del pueblo, la decisión de amnistiar a Chávez. "Chávez trajo a Caldera y Caldera trajo a Chávez", será el dicho popular que sintetice la secuencia política. El "caracazo" y las dos asonadas habían obligado a Caldera a buscar un discurso más populista y fue entonces cuando el ex teniente coronel de paracaidistas supo cuál era en realidad la consistencia del régimen y decidió que había llegado su momento. Con Chávez en la calle y ante el fracaso de los intentos regeneracionistas antipartitocráticos, la crisis de legitimidad se agudizaba hasta alcanzar plena expresión política. Todas las fuerzas políticas se aglutinaron contra él, incluidos patronal, Iglesia y sindicatos, pero Chávez combatió electoralmente a los "escuálidos" oligarcas hasta su derrota electoral. Juró su cargo de Presidente sobre la "moribunda" constitución de 1961 y al cabo de año y medio la cambió e instauró la quinta república. Su intervención como gran líder carismático le llevó a entrar en la historia del país, modificando el nombre y su bandera.

\footnotetext{
${ }^{9}$ Citamos por Richard Gott, Hugo Chávez y la revolución bolivariana, Madrid: Foca 2006, p. 77.
} 


\section{LA PROTESTA CIUDADANA}

A partir del "caracazo" aumentan las protestas y se hacen más directas y violentas. Desde octubre de 1989 se producen 8.355 protestas, una media de 2,08 protestas diarias, sin contar paros ni huelgas. Durante los años de 1991 a 1994 la media sube a 2,75 protestas. En los años 1999 y 2000, los dos primeros años de gobierno chavista, la media ascendió aún más, alcanzando a 2,83 protestas diarias. ${ }^{10}$ Siguiendo las noticias publicadas por el periódico El Nacional, en los años previos a 1989, la mayoría de las protestas eran marchas anunciadas y pacíficas, pero después abundan las marchas no permitidas, el corte de calles, los llamados "disturbios"; asimismo, las violentas empiezan a hacerse cada vez más visibles $^{11}$. Los partidos políticos dejan de cumplir su función mediadora y su deterioro se precipita.

\section{LA SOCIEDAD CIVIL}

El movimiento vecinal fue el protagonista de la sociedad civil. Sus inicios están vinculados a carencias urbanas y a violaciones de ordenanzas urbanísticas. Luego irían evolucionando hacia otros ámbitos de participación política y actuaron en áreas de políticas públicas, ganándole espacio a los partidos políticos. Se oponían a las listas cerradas y pedían elecciones uninominales. En 1989, la Ley Orgánica de Régimen Municipal creó la figura del alcalde, elegible por decisión popular. A la discusión sobre la uninominalidad se unía una crítica al establecimiento político y su falta de democracia interna. Según un estudio de Consultores $21^{12}$ de 1996, la confianza en las asociaciones de vecinos es superior a cualquier otra institución política: las universidades lideran el ranking con un índice de confianza de 2,95, las asociaciones de vecinos, con un índice de 2,36, se sitúan en quinto lugar tras la iglesia católica, los medios y las fuerzas armadas, el parlamento nacional ocupa el penúltimo lugar, con un índice del 1,70 y los partidos políticos el último, con el 1,63, tras el poder judicial, la policía y las

${ }^{10}$ Cif. Margarita López Maya, "Venezuela después del Caracazo: Formas de protesta en un contexto desinstitucionalizado", Working Paper 287, July. En:

http://www.nd.edu/ kellogg/publications/workingpapers/WPS/287.pdf

${ }^{11}$ Cif. Margarita López Maya, op. cit., p. 7.

${ }^{12}$ Consultores 21, Venezuela Democratica Culture: Analitical Report on Poll Results, enero 1996. La encuesta se realizó en Caracas, Maracaibo y Mérida. Véase Carmen Beatriz Fernández, "Partidos políticos y sociedad civil en Venezuela: historia de amor y odio", Espiral, vol. 8, no 22, Universidad de Guadalajara, Guadalajara, México, pp. 63-89, p. 70. 
uniones de trabajadores ${ }^{13}$. Más del $40 \%$ de la población pensaba que "casi todos los adecos y copeyanos son corruptos"14, esto es, los miembros de los dos partidos que llevaban gobernando Venezuela desde 1961.

Si bien Chávez dio cabida en su discurso a los movimientos ciudadanos, en el sistema electoral seguido para elegir a los miembros de la Asamblea Constituyente se privilegiaron a los candidatos con apoyo presidencial, expresado a través de listas de identificación, las populares "chuletas", un equivalente funcional de las listas cerradas. El $60 \%$ de chavistas que concentraron el voto obtuvieron el $94 \%$ de los representantes, mientras que el otro $40 \%$ que dispersó el voto obtuvo un $6 \%{ }^{15}$. La división se manifestó pronto. Elías Quintana, líder del movimiento vecinal y miembro del partido Queremos Elegir, veterano representante de la sociedad civil, señalaba que la sociedad civil es distinta de la sociedad en general y que no tiene "un vocero único". A lo que Chávez respondió en términos de "señor Santana (...) llame usted a la sociedad civil suya a una esquina y yo llama a la mía a la otra." ${ }^{16}$ La secuencia ha sido, en primer lugar, una alianza con la sociedad civil antes de las elecciones, para luego deshacerse de ella. Es el momento de la democracia plebiscitaria del líder.

\section{LA EVOLUCIÓN POLÍTICA}

\section{LAS RAÍCES DE HUGO CHÁVEZ}

En las décadas de los 60 en Venezuela hubo una guerrilla de inspiración guevarista. Muchos supervivientes se reagruparon en el Movimiento al Socialismo (MAS), en el Partido Comunista y en el Partido Revolucionario Venezolano (PRV), liderado por Douglas Bravo. Según Alberto Garrido ${ }^{17}$, el golpe de 1992 se origina en la guerrilla de los 60, concretamente mediante el impulso de Douglas Bravo. Este veterano guerrillero no acepta la derrota y desde el Partido Revolucionario Venezolano comienza a infiltrar a las fuerzas armadas venezolanas creándoles expectativas de que algún día se darán las condiciones necesarias para una insurrección cívico-militar. El bolivarismo surge en este contexto como una mezcla de nacionalismo, populismo y lucha contra la

\footnotetext{
${ }^{13}$ Cfr. Carmen Beatriz Fernández, op. cit., pp.70-71.

${ }^{14}$ Cfr. Carmen Beatriz Fernández, op. cit., p.72.

${ }^{15}$ Cfr. Carmen Beatriz Fernández, op. cit., p.75.

${ }^{16}$ Cfr. Carmen Beatriz Fernández, op. cit., pp.77-78.

17 Alberto Garrido, La historia secreta de la revolución bolivariana, Editorial Venezolana, Mérida, 2000.
} 
oligarquía, tomando las ideas de Bolívar, Simón Rodríguez y Ezequiel Zamora. A este partido pertenecía Adán Chávez, hermano mayor de Hugo y profesor de la Universidad de los Andes, Mérida. Hacia 1982 o 1983, Adán puso en contacto a su hermano con Douglas Bravo. Al principio, según Bravo, Chávez quería que se tratase de un movimiento cívico-militar. Quería evitar que pasase lo que en Perú en los años 70, cuando el fracaso del general Velasco Alvarado fue consecuencia de la ausencia de participación de civiles. Estaba de acuerdo en aguardar a un acontecimiento que causase una gran expectativa en las masas populares y a que los militares participantes en la conspiración tuviesen mando de tropa. En 1992 todos tenían 40 años. El "caracazo" sería el acontecimiento esperado, pero en esos diez años ocurrieron algunos cambios.

Chávez sugirió a La Causa $\mathrm{R}$, un partido de izquierdas, que organizara batallones de civiles de carácter paramilitar, listos para cooperar con el ejército, una organización similar a los "Batallones Dignidad" que Torrijos creó en Panamá. Pero los civiles se mostraban pasivos cuando no recelosos de la alianza con los militares. Tras el "caracazo", Bravo se reúne con Chávez. El líder guerrillero ya opinaba que Chávez no quería que los civiles participaran como fuerza concreta, sino que la sociedad civil aplaudiera. La intención de Chávez era convocar a los civiles una vez que estuvieran en el poder. Seguía contando con los partidos de izquierda, pero temía que pusiesen en peligro la conspiración, que fuesen descubiertos. Para las elecciones de 1998 volvió a contar con ellos, pero esta vez iban de comparsa. Chávez razona políticamente por qué les dejaba fuera:

“(...) Uno de los efectos desdichados de la guerra de guerrillas en Venezuela fue el aislamiento de líderes políticos que de otro modo podrían haber contribuido al desarrollo de una mentalidad y perspectiva diferente en el país (...) Ha habido un enorme vacío de liderazgo (...) Dada esta situación histórica, tenemos que dedicarnos a transformar la conciencia colectiva mediante la acción (...) Tenemos que llenar el vacío, crear un nuevo liderazgo"18.

Para las elecciones de 1998 se alió de nuevo, a principios de año, con partidos izquierdistas en una agrupación llamada Polo Patriótico. Pero poco a poco se fue manifestando que, pese a la vacuidad doctrinal e ideológica del Movimiento $\mathrm{V}$ República, la fuerza dominante era el carisma del candidato a presidente. El Polo Patriótico obtuvo un 56,90\% de los votos que, repartidos, correspondían en un $40,17 \%$ del electorado al MVR y el resto hasta 56,90 \% al resto de partidos

${ }^{18}$ Cfr., op. cit. p. 69 y 70. 
juntos. Los primeros años hubo miembros de otros partidos en ministerios de la V República, pero poco a poco fueron rompiendo con Chávez o fueron destituidos por él. Por otra parte, el MVR es un cascarón vacío, carece de una organización independiente del líder, nadie conocía dónde estaban sus sedes. Su logo era una imagen de Chávez vestido con el uniforme del cuerpo de paracaidistas, recordando el día del golpe del 92 y adoptando una pose que recuerda vagamente al Che; un logo que identifica al partido con el líder. Además, nadie conoce a sus seguidores como emeverristas, sino como chavistas. La ideología del partido era vaga, así como el contenido de la revolución bolivariana y del socialismo del siglo XXI. En la página web oficialista "aporrea.org" pueden leerse tras diez años desde su fundación la concreción de la ideología bolivariana en "la comunión del corazón y la mente (donde) el corazón es la guía de la mente". ${ }^{19}$

Esta sensibilidad religiosa ("comunión”, “corazón") que Chávez supo instrumentalizar desde muy pronto, tiene que ver con la gran penetración que las sectas protestantes habían logrado en Venezuela, especialmente entre sus capas populares. El pueblo estaba acostumbrado a un lenguaje misional, milenarista, así como a imágenes redentoras, precisamente las que Chávez usó, junto con el logo del MVR, en la campaña electoral de 1998 y que le han acompañado hasta el referéndum por la reforma constitucional de diciembre de 2007, uno de cuyos ejes discursivos fue que "Cristo fue el primer socialista" y la divulgación en los medios de una imagen de Jesús levantando el puño izquierdo. A ello hay que añadir que para el año de la primera campaña electoral, a dos años para el cambio de milenio, se había extendido en Caracas la idea New Age de la Quinta República que la identificaba con la Quinta Monarquía, una utopía milenarista inglesa del siglo XVII que afirmaba que tras las monarquías de Babilonia, Persia, Grecia y Roma venía el Gobierno de los Santos, que traería la abolición de los impuestos, la reforma de las leyes, la humillación de los ricos y la exaltación de los pobres ${ }^{20}$. La vuelta de las religiones y de los cultos se había dejado sentir en Venezuela al tiempo que se vivía la peor crisis institucional de su historia reciente, lo que abonó el terreno para que el carisma obrase sus efectos.

\footnotetext{
${ }^{19} \mathrm{Cfr}$. http://www.aporrea.org/imprime/a50134.html

${ }^{20}$ Cfr. Gott, op. cit. pp. 149-150.
} 


\section{CHÁVEZ COMO POPULISTA DE IZQUIERDAS}

Como ya dijimos, el populismo es una variante de la dominación carismática, que objetiva el carisma en abstracciones como "pueblo" o "patria" y lo rutiniza en instituciones vacías de contenido vinculadas directamente con el líder. En un primer momento funciona casi exclusivamente el carisma personal, la adhesión. Luego se incorpora la fe en la realizabilidad de las metas, las objetivaciones del carisma. Y luego, con la rutinización del carisma, con la creación de instituciones que están prácticamente vacías dirigidas personalmente por el líder. Pero en principio, la objetivación es el elemento central del discurso, el que vehicula la vinculación directa entre el líder y sus seguidores, así como la rutinización, la creación de instituciones organizativas que se corresponden con el propósito de (re)crear la comunidad perfecta o caminar unidos en pos de ella.

\section{VINCULACIÓN DIRECTA LÍDER-MASA}

En 1998, antes de las elecciones, era frecuente ya escuchar y leer sobre el carisma de Chávez. Pero un líder carismático genuino muestra su condición desde antes de llegar al poder.

Douglas Bravo lo define como un hombre "carismático" y un "líder natural". Un colaborador de ambos, Nelson 'Harold' Sánchez también menciona su "carisma" y la facilidad con que "se gana al pueblo" ${ }^{21}$. Chávez era también un hombre más preparado de lo que parecía. Era un hombre en parte cultivado, tenía un postgrado en ciencias políticas, escribía poesías, era de clase media pero nacido en un pueblo y tuvo sensibilidad y tacto para tener familiaridad con el pueblo, al contrario de la inmensa mayoría de las clases medias, que le vuelven la espalda. Poseía autoconfianza y un gran sentido misional. Tales son los rasgos que aparecen en la biografía de Ángela Zago, Rebelión de los Ángeles. (73, 74, 78; Hawkins, 1147). Freddy Domínguez ${ }^{22}$, llegaría a ser ministro de Chávez y su biografía es la propia de un apasionado. Lo considera "profundamente penetrante en los sentimientos del pueblo, que no tiene dudas acerca de las convicciones del líder"23.

${ }^{21}$ Los entrecomillados en Kirk Hawkins, "Populism in Venezuela: the rise of Chavismo", in: Third World Quartely, Vol 24, № 6, pp. 1137-1160, 2003, p. 1146.

${ }^{22}$ Freddy Domínguez, Chávez: La revolución pacífica y democrática, Caracas, 1999, p. p.131.

${ }^{23}$ Freddy Domínguez, Chávez: La revolución pacífica y democrática, Caracas, 1999, p. p.131. 
En la Introducción al libro de Agustín Muñoz Habla el Comandante, Chávez maneja el lenguaje político propio de la izquierda latinoamerica revolucionaria. Lo interesante es el lugar donde se ubica en el proceso. Chávez señala que Venezuela está en condiciones que presagian una nueva época, pero - señala - el agente del cambio "debe ser el viejo y familiar caudillo salvador con su acento mesiánico." ${ }^{24}$ Su definitiva visibilidad por parte de las masas de su carisma y, por tanto, la extensión del mismo se produjo en la intervención televisiva tras el fracasado golpe de 1992.

Como hemos visto, esto fue tan evidente que el líder democristiano Rafael Caldera reconoció la nueva situación política del país y quiso atraer hacia sí a los votantes. En vano. Una vez fuera de la cárcel, Chávez recuperó en poco tiempo el fervor popular y adquirió un capital político concentrado en torno a su persona que tan sólo perdería en el referéndum sobre la reforma constitucional, donde perdió por un estrechísimo margen.

\section{DISCURSO}

Su discurso maniqueo, como señala Vivas, se basa en un mensaje sencillo: "vosotros, pueblo de Venezuela, no tenéis ninguna culpa; vosotros sabéis quienes son los culpables de lo que nos ha pasado, y yo voy a deshacerme de esa gente que nos rodea, no lo dudéis. Y todavía más, voy a resolver vuestros problemas." ${ }^{25}$ Sin embargo, el cambio político no basta para enrumbar al país hacia la prosperidad económica. Hace falta que el país abandone la percepción de que Venezuela es un país rico por sus enormes reservas petroleras, lo que conduce a la mentalidad rentista, sea cual sea el signo político del gobierno, incluso si se trata de una revolución socialista; conduce a la identificación de la economía exclusivamente con el gobierno y sus distribuciones clientelares y con el "pónganme donde haiga", la divisa del país.

Para comprender la fuerza de su discurso hay que tomar en consideración que ya entonces Venezuela era un país con un $40 \%$ de pobres y muy pobres y dos tercios de la población con problemas para llegar a fin de mes; las clases acomodadas se referían en determinadas circunstancias a esa mayoritaria de población, especialmente a la que vivían en los ranchitos, llamándoles 'monos'. No sólo estaban excluidos social y económicamente, sino que, según se deduce de

\footnotetext{
${ }^{24}$ K. Hawkins, op. cit. p. 1148.

${ }^{25}$ Leonardo Vivas, Chávez, la uúltima revolución del siglo, Planeta, Caracas, 1999, p. 72.
} 
la semántica, estaban excluidos de la humanidad. Chávez no sólo se refiere a ellos y les sitúa en el centro de su discurso, no sólo los invita a una 'democracia participativa' y a una 'revolución protagónica', sino que castiga a los ricos en su nombre. Desarrolla así un discurso maniqueo que mantiene polarizada a la ciudadanía, en perpetuo estado de mutua sospecha, y que sirve para mantener en estado efervescente la conciencia y la sensibilidad de sus seguidores. Se refuerza así su adhesión, se acredita el carisma del líder, y se van ganando batalla tras batalla electoral. Desde 1998 a 2007, cuando Chávez pierde el referéndum para modificar la Constitución, aunque luego lo repitió y lo ganó amenazando al pueblo con perder los beneficios económicos que les había otorgado, hubo seis convocatorias electorales.

Por otra parte, Chávez se dirigía al pueblo en un programa de varias horas de televisión llamado Aló Presidente. En un país en que, como hemos dicho, habían penetrado las sectas protestantes, Chávez usaba contraposiciones sencillas. Muestra a la vez un trato familiar, sin protocolos, con sus ministros. Muchas veces dice las leyes que va a hacer o las medidas que va a tomar allí mismo. El pueblo se siente en el intríngulis del poder. En ocasiones se gira mirando a otra cámara y se pone frente al televidente de las áreas rurales y las barriadas pobres. Hace de la audiencia una comunidad, del discurso una comunión. Se vale de su facilidad de palabra, de su lenguaje vivaz, de haber sido hijo de maestros, de su éxito docente como profesor en la academia militar; pero sobre todo se vale del hecho de que sabe ponerse en el papel de un predicador evangélico, de que maneja el lenguaje bíblico. "Aquí huele a azufre", dijo en la ONU. No fue un chiste. Esta falta de contenido ideológico de sus discursos, que contrasta con un hombre leído y versado en las teorías revolucionarias de izquierda, fue la que provocó que todos los partidos u organizaciones que lo apoyaron en 1998 se desvincularan de él.

\section{EL CULTO A BOLÍVAR. EL TRASFONDO HISTÓRICO Y RELIGIOSO}

"Nosotros", dijo Chávez en su discurso de 1999 a la Academia Militar, "tuvimos un día que retomar el látigo y llegar al templo a sacar a los mercaderes." ${ }^{26} \mathrm{El}$ templo al que se refiere es el de la patria. El sentimiento que predominaba por entonces, recién aprobada la nueva constitución, cambiado el nombre del país y retocada la bandera era el de resurrección. La identificación con Jesús lo hace más evidente aún. En Habla el Comandante se refiere a la figura central en estos

${ }^{26}$ Salas de Lecuna, p. 203 
términos: "Dios es el Cristo que fue crucificado para luchar junto con el pueblo contra un imperio, el Cristo que según la doctrina cristiana bajó de la cruz, resucitó y vino al mundo para luchar por los desposeídos."27 Saber conectar con lo más santo de la tradición popular venezolana ha sido la principal virtud del discurso de Chávez.

En Venezuela pueden distinguirse dos polos del culto a Bolívar: uno oficial y otro popular. El oficial ha sido estudiado por el historiador Germán Carrera Damas:

"(El) culto a Bolívar (es) un sistema paralelo de creencias religiosas," escribe el historiador Carrera Danas, "una suerte de religión civil, que busca formar un ámbito ideológico mediatizador. Bolívar ha de representar, por ejemplo y amén de los valores morales y éticos todos, la nación y el nacionalismo, la democracia y aún el populismo, cualquiera que sea la versión de éste último, ya de derecha, ya de izquierda". ${ }^{28}$

Bolívar no fue sólo el Libertador, el héroe nacional venezolano, sino que él mismo fue actor y parte de un drama histórico que todavía hoy se sigue representando: el drama de la constitución de las sociedades postcoloniales, el drama de la superación tentativa de sociedades duales, el drama de la emergencia del Leviatán Caribe. Bolívar significó entonces y simboliza todavía hoy la liberación y fundación originaria de la nación mediante la sustitución de una violencia mala (la de la conquista) por otra buena al servicio del pueblo. La gesta heroica de Bolívar se inscribe así en ese magma mitogénico en que se gestan las epopeyas nacionales. Antes de la independencia, Fray Servando de Mier escribía: "La América es nuestra, porque nuestros padres la ganaron si para ello hubo un derecho; porque era de nuestras madres, y porque hemos nacido en ella". ${ }^{29}$

La conciencia de identidad pasaba por asumir, como hijos de esa violencia/violación primera, la herencia paterna de la conquista, "si para ello hubo un derecho," y, "naturalmente", la materna, la herencia de la comunidadmadre: "porque era de nuestras madres". Tal fue la labor de Bolívar: rescatar a la madre del padre violento y entregársela nuevamente a sus hijos. El ciclo "liberación de la patria" (identificación con la madre sometida), entronamiento

${ }^{27}$ Kirk Hawkins, op. cit., p. 1154

28 Cf. Germán Carrera Damas, Venezuela: proyecto nacional y poder social, Barcelona, Editorial Crítica 1986, p.112 y ss.

${ }^{29}$ Citamos por Nelson Martínez Díaz, La Independencia hispanoamericana, Madrid, Historia 16, 1999, p. 11, que, junto con la obra citada de Carrera Damas y la de Vallenilla Lanz nos ha servido de referencia básica para la historia de Venezuela. 
del hijo-héroe nacional suele conducir a un nuevo ciclo de corrupción, salvación de la patria, etc. Que constituye el tipo ideal en que la identidad nacional y el cambio político adquieren unidad interpretativa. El insuficiente desarrollo económico y social de Venezuela, para la cual no habían cambiado sustancialmente las condiciones de vida, explica la aparición recurrente de fenómenos populistas.

Todo cambio político se anuncia por la corrupción, pues ésta es vista con razón como traición a la nación, porque es la traición a la promesa fundacional hecha al pueblo: "somos una nación", cuando en realidad los corruptos, la oligarquía, las multinacionales piensan en términos egoístas, no de nación (no distribuyen). Invocar la corrupción es invocar la promesa violada, es denunciar que para las clases altas la nación es menos importante que su interés egoísta de clase; es, pues, recordar que la república sigue estando en el mismo estado de ilegitimidad que los patriotas atribuían a la época colonial. La corrupción niega la obra de Bolívar, vuelve a separar lo que Bolívar unió, y bajo los ropajes nacionales de los oligarcas aparece de nuevo la sistemática rapacidad del corrupto. Así se forma el contexto en que un nuevo candidato a héroe nacional ha de rescatar a la madre patria maltratada a cuya costa se están dando un licencioso festín los oligarcas. Y llega el momento de echar a los mercaderes del templo de la patria.

Yolanda Salas $^{30}$ ha estudiado el fenómeno del bolivarismo en Venezuela preferentemente en el campo de la historia oral. Ha estudiado cómo se verbalizan y dramatizan los mitos, así como las estructuras profundas y los arquetipos culturales que modelan la conciencia colectiva. "En este sentido", escribe "la verdad de la Historia Oral Tradicional es sociológica, y su axioma no cuenta con el respaldo sólido y confiable que ofrecen las fuentes escritas. Sin embargo, añade, "lo que la gente cree y afirma sobre los hechos reales representa una valiosa fuente documental para la comprensión y explicación del imaginario

${ }^{30}$ Cf. Yolanda Salas, "La dramatización social y política del imaginario popular: el fenómeno del bolivarismo en Venezuela", en Daniel Mato (comp.), Estudios Latinoamericanos sobre cultura y transformaciones sociales en tiempos de globalización, CLACSO, Buenos Aires, 2001. La obra básica de la autora, a la que hace constante referencia en esta investigación, es Yolanda Salas de Lecuna, Bolívar y la historia en la conciencia popular, Instituto de Altos Estudios de América Latina de la Universidad

Simón Bolívar, Caracas, 1987. 
colectivo. En la subjetividad del testimonio", concluye, "yace precisamente su valor, pues allí se revelan mentalidades, valores y construcciones culturales". ${ }^{31}$

El trabajo de Salas escarba en discursos como la promesa presidencial ante la Academia Militar de "sacar a flote a la patria del saqueo más grande que se tenga memoria en 200 años de historia republicana (que) con la corrupción, con el mal ejemplo y con la impunidad, estaba horadando los valores sagrados de la Patria"32. Por otra parte, la visión de Bolívar entre el pueblo venezolano, siempre siguiendo la investigación de Salas, puede apreciarse en estas muestras:

Para mí, Bolívar fue como una cosa que Dios mandó para darme la 'libertá' de los españoles, porque éramos esclavos de ellos. Él no era una persona de carne humana como uno. Nunca manchó su espada ni mató. Eso sería bendición de Dios que mandó eso.

Usted sabe que nuestros padres desde el momento que uno nace le hacen ver cómo es Bolívar. Y que Bolívar es prácticamente parte de Dios que hay que respetarlo. Usted sabe que esas son las primeras cosas que le enseñan a uno.

Lo más grande que hizo Bolívar fue la libertad que concedió a los esclavos.

El hombre fue un segundo Jesucristo, porque nadie es capaz de hacer lo que hizo Bolívar. Si Bolívar naciera de nuevo, más de uno correría: esa pila de bandidos que no han sabido manejar los dineros de este país nuestro. Bolívar no puede descansar en paz, porque es un país donde tanto ha fallado. ${ }^{33}$

Hay dos cultos: uno de raíz popular, gestado paralelamente al culto bolivariano oficial letrado. En este sentido, es importante destacar la diferencia de ambos cultos. El oficial, tratado extensamente por el historiador Carrera Damas y por Castro Leiva ${ }^{34}$, representa la base donde se forjó la conciencia nacional. Las metamorfosis del significado e impacto de Bolívar en la conciencia popular, por otro lado, revelan las significaciones que sobre el héroe se han formulado en el espacio de la exclusión social y al margen de los ideales y límites de la nación formulada por la cultura letrada. Un Bolívar santo, mitificado, reivindicador de

${ }^{31}$ Cf. Yolanda Salas, op. cit., p. 202

${ }^{32}$ Para las citas véase Yolanda Salas, op. cit. p. 203

${ }^{33}$ Cf. Yolanda Salas, op. cit., p. 205

${ }^{34} \mathrm{Cf}$. Germán Carrera Damas, El culto a Bolívar. Esbozo para un estudio de las ideas en Ve n e z u e la, Universidad Central de Ve n e z u e l a, Ediciones de la Biblioteca № 46, Caracas, 1973 y Luis Castro Leiva, De la patria boba a la teología bolivariana, Monte Avila Editores, Caracas, 1991. 
las clases que se sienten fuera de las esferas del poder, que emergió de las verbalizaciones colectivas populares, así como el espíritu mesiánico del culto.

"Bolívar", escribe Salas, "héroe cultural, fundador y civilizador de naciones, convertido en Padre de la Patria, encarna dentro de esa tendencia al profeta que se retiró del reino de este mundo y dejó tras de sí un mensaje que el sentir popular ha transformado en esperanza. De esta forma, Bolívar confirma su asistencia espiritual desde el más allá y queda abierta la posibilidad de un retorno. Bolívar el predestinado, mensajero divino, especie de santo guerrero, no descansa en paz desde su tumba y vela por su Patria, ofrece alivio a los desamparados, es un luchador infatigable por la justicia, por las necesidades de los pobres, por la libertad, abre caminos y genera sentimientos mesiánicos en sus admiradores y adeptos, quienes esperan una nueva liberación. Esta esperanza de liberación se objetiva en una nostalgia por el pasado o en un deseo por un mundo social más justo. Nostalgia que propicia expectativas enunciadas en frases como 'las cosas cambiarían con otro Bolívar' o 'sólo otro Bolívar podría salvarnos'... Bolívar, héroe épico y libertador", continua Salas, "es transformado por la conciencia popular en una suerte de Mesías que vino a redimirnos. Y esa conciencia histórica popular, regida también por una concepción épica y mitificadora de los procesos históricos pasados, ha propiciado y propicia un quehacer nacional a linajes de caudillos guerreros cuyas acciones reiterativas, especie de ciclos por cumplir, reproducen las del Mesías Bolívar"35.

No es de extrañar que en la alocución televisiva de Hugo Chávez, con su aire juvenil, su seguridad en sí mismo, en esa frase "hemos fracasado por ahora, tiempos mejores vendrán", muchos vieran al emisario heroico que esperaban. "Chávez es la encarnación de un maestro de luz, de un espíritu de libertador. No de Bolívar. Bolívar subió muchas escalas espirituales por lo que hizo, pero como los grandes profetas, no tiene que encarnar: tiene sus emisarios"36. Más adelante él mismo diría: "En el ejército mandamos Dios, Bolívar y yo".

\section{LUCHAS SOCIALES Y CAUDILLISMO}

Vista con suficiente perspectiva, la crisis de la España colonial se hace inteligible como un proceso de repentino colapso del sistema de poder de la Metrópoli. Si la

${ }^{35}$ Cf. Yolanda Salas, op. cit., p. 206

${ }^{36}$ Testimonio expresado en estado de trance por un líder médium de un conocido centro espiritual religioso en Caracas, marzo de 2000. Citado en Yolanda salas, op. cit., p. 209 
invasión napoleónica actuó como motor, pues hizo que se transformaran en Juntas Generales los cabildos americanos a imitación de las Juntas de Cádiz, la restauración de Fernando VII significó la radicalización del movimiento americano. Si en la península quedaría una guerra civil soterrada durante el siglo $\mathrm{XIX}$, en América esa guerra civil continuada se manifestó en la sucesiva sustitución de unos caudillos por otros a lo largo del siglo XIX. Contando la última, Venezuela ha conocido 23 constituciones. La causa es que los patriotas pusieron en marcha un proceso emancipador que constituyó una revolución política sin apenas modificar las estructuras socioeconómicas. Según la tesis de Vallenilla Lanz la independencia es primeramente un conflicto civil entre las fracciones de la clase dominante por reestructurar el poder político una vez roto el nexo colonial monárquico. En ese contexto, las promesas de igualdad a indios y negros para que se sumen al bando patriota, serán traicionadas y las jóvenes repúblicas americanas no cambiarán en lo esencial.: inestables, premodernas, con estados débiles y comerciales dependientes en lo político y en lo económico de Inglaterra primero y de EEUU después.

La independencia nacional fue el lema ideológico bajo el que Bolívar transformó una guerra civil por la reconstitución del poder criollo, pero el resultado fue precario y contradictorio. Tan sólo la batalla de la legitimidad del poder cabe apuntarla en su haber. El miedo a los pardos tras su liberación en los años de 1813 y 1814, cuando el decreto de "Guerra a Muerte", dota a la guerra de un sentido nacionalista, pues hasta ese momento era vista como una confrontación civil. "Españoles y canarios, contad con la muerte, aun siendo indiferentes, si no obráis activamente en obsequio de la libertad de Venezuela. Americanos, contad con la vida, aun cuando seáis culpables." ${ }^{37}$ Esto significó la preeminencia, a efectos militares, de la oposición patriolista/realista (guerra de legitimidad) frente a la social y económica amo/esclavo o blanco/no blanco, e hizo que el poder real, finiquitada ya la Gran Colombia, acabase en manos de Páez, el general patriota de Los Llanos. Fue en sentido estricto un compromiso histórico, un compromiso de las fuerzas sociales existentes expresado y articulado militarmente en torno, por un lado, a los estados federales, y, por otro, a la dominación caudillista por los métodos propios de una sociedad cuasi tribal. La clase dominante, tras haber abierto la caja de Pandora y haber invocado al pueblo, pero temerosos al fin de los conflictos de los pardos movidos por sus deseos de libertad, y con el precedente de lo que había ocurrido en Haití en la retina colectiva, acabó por asumir una dura lucha en pos de la recuperación de su poder interno sobre la

${ }^{37}$ Nelson Martínez Díaz, La Independencia Hispanoamericana, Historia 16, Madrid, 1999, p. 113 
base legitimadora de la ruptura definitiva del nexo colonial. El exponente de esta lucha, su instrumento y su artífice, fue Simón Bolívar. Bolívar se erigió en símbolo de una unión nacional que de hecho no se alcanzó, pues independencia seguía siendo un término dual: independencia del yugo monopolista para unos, independencia del yugo de la esclavitud para otros. Por eso Bolívar cumple a la perfección su papel de símbolo: enlaza lo afectivo con lo racional, condensa en el plano afectivo lo que de hecho y a todas luces está disociado, funde los anhelos de libertades distintas y enfrentadas con un discurso propio que remite a un proyecto racionalizador foráneo y moderno: la construcción de un mercado nacional y una administración nacional, proceso que se estaba dando en Norteamérica y Francia. Bolívar simboliza la unión porque impide ver la desunión esencial y constitutiva de sociedades que aún hoy, en términos económicos y sociales, son tan duales como en los tiempos de la colonia. Vallenilla Lanz primero y Carrera Damas después, al reflexionar sobre las diferencias entre esas revoluciones y la independencia sudamericana, constatan que, ciertamente, en EEUU también había negros, pero no llaneros-beduinos como en Venezuela, reacios a toda organización social; que en Francia había pobres, pero también había una administración y un funcionariado moderno asentado ya en los tiempos del Absolutismo. Ni Francia ni Estados Unidos eran "repúblicas aéreas", como dijo el Libertador de Venezuela, construidas retóricamente con materiales a medio cocer; ni "hicieron leyes para los ángeles", como dictaminó Víctor Hugo décadas después refiriéndose a la constitución de Colombia. Eran sociedades ya constituidas que con la revolución cambian de caparazón exterior. Esto fue lo que descubrió Bolívar al final de su vida cuando confió contra su propia ambición el gobierno a Páez; y esto fue lo que redescubrió Vallenilla Lanz.

En 1811, constituida la I República de Venezuela presidida por Francisco Miranda, se intenta como primer paso consolidar la propiedad privada y obligar a los llaneros del interior a registrarse como trabajadores de alguna hacienda. Miranda quería impulsar una revolución modernizadora de corte burgués, pero este impulso fue el motivo por el que se atacó a la recién instaurada república. El ataque no procedió de la oligarquía comercial caraqueña, sino del interior, de Los Llanos. Su estructura social era por entonces como el de las sociedades sin estado, llaneros-beduinos, como los denomina Vallenilla Lanz. Su organización política era primaria: el más fuerte de entre ellos era el caudillo de las razzias, el único que por su autoridad personal mantenía unido al resto. Uno de estos caudillos era Boves, un asturiano rudo y sagaz que consiguió aunar un ejército de llaneros, cimarrones y negros. Su divisa era la guerra a los blancos y el reparto de sus 
tierras y propiedades entre indios, pardos y negros. En la retina criolla estaba la visión de la independencia de Haití, versión caribe de la guillotina parisién contra los terratenientes blancos.

Boves, en lucha contra los patriotas, había puesto en acción las fuerzas que acabaron derrotando a la república, pero dio comienzo a una guerra de clases que hacía ya inviable el retorno al orden constitucional ${ }^{38}$.

A lo largo de esta lucha militar va surgiendo el pensamiento político de Bolívar. Al principio, cuando la I República, Bolívar está fuera de Venezuela. En 1812 sustancia su teoría de la emancipación en el "Manifiesto de Cartagena." En la "Carta de Jamaica" de 1815 tratará de llamar la atención de las potencias europeas para que apoyen la emancipación. Esos años se corresponden con su etapa más creativa. Pero su verdadero éxito se debe a haber sabido aprovechar una coyuntura militar que se da entre 1813 y 1814, cuando la estructura de poder interna sufre una gran dislocación. Es el momento en que dicta el decreto de "Guerra a muerte." Ahí es donde logra el éxito ideológico y militar que se plasma en la concreción de la teoría de la emancipación de 1815 desde su inicial esbozo en 1812. La oposición que él logra que predomine es la de patriota/realista frente a la de carácter económico y social amo/esclavo o blanco/no blanco. La doctrina abolicionista tiene un origen específico en la situación militar. Cuando en 1815 trata de atraer el apoyo de las potencias europeas, sólo Haití se lo brinda pero a cambio de decretar la abolición de la esclavitud. Tras la muerte de Boves y la llegada del general español Morillo con una tropa de 30.000 hombres se produce una situación imprevista: se disuelven los ejércitos llaneros, pues Morillo confía en los regulares. Los llaneros se pasaron a las filas patriotas junto con los negros emancipados por el decreto de 1816, el decreto que Bolívar se comprometió a firmar con Haití. Es el principio del fin para la causa realista. Los llaneros encontraron en el general Páez, de corte similar a Boves, a su nuevo caudillo, que infligiría sucesivas derrotas a Morillo y que liberará la Gran Colombia que se materializará, aunque por poco tiempo, en el Congreso de Cúcuta de 1821. Un año antes, el pronunciamiento de Riego en España paralizó la expedición que debía dirigirse a América, por lo que en noviembre de 1820, en Trujillo, Venezuela, se firmó el cese de las hostilidades. En la Constitución que el propio Bolívar redacta para el Congreso de Angostura se proponían algunos cambios, entre otros, la postergación sine die

${ }^{38}$ Cfr. Nelson Martínez Díaz, op. cit., p.115 
de la abolición de la esclavitud. La revolución emancipadora comenzaba a ser un restablecimiento del orden interno colonial.

Casi tres años antes del incidente verbal entre el hoy rey emérito y el mandatario venezolano, el 12 de octubre de 2004, fue derribada la estatua de Colón. Varios grupos chavistas lo acusaron de genocida. Fue un acto ritual más para reivindicar a ese sujeto social surgido en la colonia y traicionado una y otra vez, de Páez hasta después por Nicolás Maduro. "Se evidencian, en las representaciones de sí mismo y del otro - escribe la psicóloga social venezolana Mireya Lozada residuos de los mitos de la conquista y expansión española (...) La diferencia de la población entre negros, mestizos, indios, zambos y blancos de la colonia son los antecedentes de la categorización entre monos y escuálidos actuales" ${ }^{39}$. Pero hay otra diferencia. Los pardos, bastantes más en número, han sido claves en varios momentos decisivos de la historia venezolana. Lo fueron en la guerra de la Independencia; lo son con Chávez.

La guerra de la Independencia fue una batalla ideológica, una guerra política y militar, una guerra civil y una guerra social. Interesa el hecho de que fue una guerra que militarmente tuvo que recurrir a liberar a los esclavos guiados por caudillos, la autoridad que obedecían, y luego tuvieren que recurrir a caudillos, una ver fracasado el sueño republicano de Bolívar, para desactivar las fuerzas que previamente se habían desatado. De 1814 a 1817 los pardos e incluso los indígenas inclinan la balanza del lado de las tropas realistas, movidos en buena parte por la promesa del rey de privilegios y derechos que los mantuanos (la nobleza colonial) les negaban. En este terreno destaca el Llanero, mezcla de negro e indio, ligeramente ligado con sangre española. Su actividad es la ganadería, donde destaca por su utilización del caballo, tanto para el trabajo como para la guerra. Chávez es de ahí, de los Llanos, al igual que su abuelo Maisanta, un pequeño cacique local que destacó por su oposición armada al dictador Gómez. Desde este punto de vista Chávez entronca con la historia venezolana. El primer cacique llanero fue, como hemos dicho, el asturiano José Tomás Boves. El carisma de un cacique llanero es simple: sus seguidores le respetan mientras sea el más fuerte y gane batallas. Boves ganó varias, algunas decisivas. Le apodaron el León de los llanos. La fidelidad de los llaneros no dependía sólo del carisma; las guerras eran guerras de rapiña. Boves, no obstante, introdujo algunas reglas. Repartió casas y bienes de desaparecidos y muertos

${ }^{39}$ Cif. Mireya Lozada, "El otro es el enemigo: imaginarios sociales y polarización", Revista venezolana de economía y ciencias sociales, Caracas, mayo-agosto vol. 10, oㅡ 2, 2004, p. 200. 
dando papeletas de propiedad. Daban propiedad a los esclavos y declaraban comunes las tierras donde habían trabajado. ${ }^{40}$

Ante esta situación, Bolívar se da cuenta que no está prima facie ante una guerra internacional, sino ante un guerra social cuyo elemento capital es la fidelidad de los pardos. Bolívar, condicionado por el Gobierno de Haití, da un giro populista en busca de una base militar y social a la que propondrá dotar, en el Congreso de Angostura, de igualdad plena.

Ya en el año 2000, el historiador y ex dirigente de Partido Comunista Venezolano en los tiempos de la lucha armada (década de los 60), afirmaba que “(...) una buena cantidad (...) de los votantes de Chávez (...) votó porque quería una dictadura" ${ }^{41}$. Y más adelante añadía: "Su apelación a la fidelidad hombre a hombre, pasando por encima de las instituciones, y su voluntad de establecer un régimen personalista $\mathrm{y}$, hasta donde sea posible, vitalicio, le asimila mucho más a los viejos caudillos del XIX latinoamericano que a cualquier otro espécimen político" ${ }^{42}$. No cabe duda que acertó en que acabaría estableciendo un régimen "hasta donde fuera posible vitalicio", ni en que una buena cantidad de sus votantes "quería una dictadura": apenas unas décimas por debajo del $50 \%$.

La estructura socioeconómica de la república que se inicia en 1830 va a ser una continuación de la estructura que existía antes de la independencia. Habían arado en un mar que les llevó básicamente al mismo sitio. La figura que dominará el siglo XIX será la del caudillo, tanto a escala nacional como local, mientras que los negocios eran llevados por los mantuanos (descendientes de españoles). Esta alianza dio estabilidad política al país y permitió el desarrollo de una economía exportadora de cacao y otros productos primarios que, sin embargo, no sirvieron para mejorar la endémica postración económica del país.

El caudillismo no era sólo producto de la guerra de independencia. En zonas poco afectadas prevalecía igualmente. En naciones extensas, poco pobladas y con un poder central débil, el caudillismo carismático era la forma de poder que protegía a la comunidad local contra injerencias exteriores, no en último lugar contra las del propio gobierno central. Tanto fue su poder que el gobierno central cayó frecuentemente en sus manos. Desde la fundación del Partido Liberal en 1840 hasta la Guerra Federal (1859-1863) se produjeron muchas

${ }^{40}$ Cfr. Germán Carreras Damas, Sobre el significado socioeconómicode la acción histórica de Boves, Caracas, Monte Ávila Editores, 1991. En especial los capítulos I y III titulados "Boves, saqueador" y "Boves, Redistribuidor de la Propiedad".

${ }^{41}$ Cfr. Manuel Caballero, La gestación de Hugo Chávez, Madrid, Catarata, 2000, p.162

${ }^{42}$ Cfr. Manuel Caballero, op. cit., p.156 
insurrecciones, guerrillas, cambios de gobierno, que aunque declinaron tras la Guerra Federal no acabaron hasta la dictadura de Gómez de principios del siglo $\mathrm{XX}$ y sobrevivieron de otra manera. Lo cierto es que durante la segunda mitad del XIX, los caudillos liberales eran el estandarte de igualdad, justicia social (campesina) y autonomía local.

\section{CHÁVEZ, EL NIETO DE MAISANTA}

Ezequiel Zamora, el "general del pueblo soberano", fue el caudillo popular más importante y recordado del siglo XIX. Junto a Bolívar y Simón Rodríguez, forma parte del acervo revolucionario chavista. El 7 de septiembre de 1846 se alzó en Guambra utilizando las consignas: Tierra y hombres libres, Respeto al Campesino y Desaparición de los Godos, ganándose la devoción popular. Tres meses dedicó Zamora a la organización de las tropas para lo que sería la batalla decisiva, como en efecto lo fue el 10 de diciembre de 1859, la famosa Batalla de Santa Inés, donde es derrotado el ejército centralista. Después de esta acción Zamora se dirige al centro del país y en el asalto a la ciudad de San Carlos, Estado Cojedes, el 10 de enero de 1860 moriría. Ezequiel Zamora nació en medio de las violentas luchas que contra España realizaban los libertadores de Venezuela. Bajo sus órdenes combatió un antepasado de Chávez, su bisabuelo, y su abuelo Maisanta lo hizo contra el dictador Gómez, contra quien se rebeló en 1914. El general Cipriano Castro, que lideraba la sublevación, lo nombró representante suyo en Sabaneta. Su abuelo le contaba las historias militares, las hazañas bélicas; pero también oía en el pueblo que su abuelo fue un "guerrillero asesino". Este conflicto fue el que hizo interesarse al joven Chávez por la historia nacional ${ }^{43}$. Zamora fue el nombre que dieron en un principio al estado federado en honor del caudillo llanero. Años después, los conservadores lo llamaron Barinas y derrumbaron varias de sus estatuas. Junto a Barinas, la capital del estado del mismo nombre, está el pueblo de Sabaneta, el pueblo de Chávez. Y no muy lejos tuvo lugar la batalla de Santa Inés, nombre de una batalla electoral de Chávez.

¿Qué fue el Comando Maisanta en la Venezuela chavista? El Comando Maisanta fue la expresión organizativa en todos los ámbitos de la geografía nacional de las fuerzas bolivarianas, para la actuación estratégica-operativa de la Misión Florentino. Misión que guía la acción revolucionaria, orientada a asegurar el triunfo electoral en el referéndum nacional del 15 de agosto de 2004, cuando se

${ }^{43}$ Cif. Agustín Blanco Muñoz, Habla el comandante, Fundación Pío Tamayo, Caracas, 1999, p. 58 
reeditará (de acuerdo al imaginario colectivo del pueblo venezolano) la derrota de la oligarquía nacional y extranjera por el pueblo soberano en la Batalla de Santa Inés, magistralmente dirigida por el general Ezequiel Zamora.

Ésta es la definición y objetivos que el Gobierno venezolano hace del comando Maisanta. Es la última batalla de aquel cacique, una batalla librada a través de su nieto. El Comando Maisanta es la estructura operativa, siguiendo su terminología, que contiene las Unidades para la Batalla Electoral (UBE), y la Misión Florentino es el nombre de la operación conjunta. Pero, ¿quién es Florentino? Este personaje nos revela un rasgo más del discurso de Chávez, su conexión con el habla llanera. "Florentino y el Diablo" es una leyenda convertida en verso por el venezolano Alberto Arvelo Torrealba, en la cual el catire Florentino se enfrenta a Satanás por medio de un contrapunteo en el que acabaría triunfando tras una fría noche llanera. El contrapunteo es una de las costumbres más arraigadas de los llaneros. La ejecutan dos o más personas que, con destreza y elegancia, echan versos improvisados. La duración depende de la capacidad creativa y la chispa de los copleros; puede durar algunos minutos o varias horas. Todavía hoy, en los festivales de música llanera, hay un renglón dedicado al contrapunteo donde se enfrentan cierta cantidad de cantantes y se premia al que demuestre mayor dominio y fluidez del verso. Chávez, que habla y "nunca vuelve al mismo tema", es depositario de esta tradición. Los llaneros, representantes de las esencias patrias (la canción venezolana por excelencia se llama Alma Llanera), son sus más fieles seguidores, como lo fueron de Zamora y de su abuelo Maisanta.

La utilización electoral que hizo de la Batalla de Santa Inés se produjo en primer lugar cuando, tras el anuncio del Consejo Nacional Electoral de que se activaba el referéndum por haberse reconocido un número suficiente de firmas, y tras algunas horas de estallidos de violencia en Caracas, Chávez salió en Palacio, retransmitido por una cadena de televisión, rodeado de símbolos religiosos e históricos. Como quiera que estaba en su momento de popularidad más baja y la victoria de Santa Inés se fraguó sobre un aparente repliegue que acabó siendo una fatal emboscada, Chávez explicó su estrategia electoral sobre esta base. La opción del NO ganó por un 58, 25\%, y la del SÍ perdió con un $41,74 \%$. En la alocución electoral tras la victoria en el referéndum revocatorio de 2004 lo recordó nuevamente. La oposición había obtenido las firmas suficientes y pedía la destitución de Chávez. La pregunta era ésta: “Está usted de acuerdo con dejar sin efecto el mandato popular, otorgado mediante elecciones democráticas legítimas al ciudadano Hugo Rafael Chávez Frías, como presidente de la 
República Bolivariana de Venezuela para el actual periodo presidencial?"44 La lucha contra el diablo la expresa el versificador llanero con un último recurso expresivo: Florentino. Había que votar 'no'. "En la batalla de Santa Inés”, relata Chávez, "Ezequiel Zamora simuló que sus fuerzas estaban replegándose, que no existían, y viene el ejército de los del 'sí', y avanza." Y continúa Chávez: “(Los enemigos de Zamora) capturaron la ciudad casi sin un tiro y Zamora se había retirado hacia el río, y resulta que les tenía una emboscada preparada, y lanzó el contraataque y los fulminó a todos, y los persiguió hasta Mérida." ${ }^{45}$ Desde la memoria colectiva de los llaneros, Chávez se desempeñaba como caudillo con la misma facilidad que lo hacía como predicador protestante frente a los habitantes de los barrios pobres de la capital.

\section{CONCLUSIONES}

En el presente trabajo hemos visto cómo surge el populimo en Venezuela tras la derrota de la legitimidad de la democracia partidista. El populismo se basa en la relación directa entre el líder y el pueblo y hemos visto las condiciones de líder de Hugo Chávez así como la visión religiosa del pueblo. Hemos visto también las características de Bolívar en sus dos cultos y su acción política en el contexto de su época, señalando la necesidad de su repetibilidad toda vez que la república venezolana no cumplió con las expectativas de Bolívar. Por último, hemos visto la dimensión caudillista de Hugo Chávez y su relación con las batallas electorales. La conjunción de estos factores fue que el chavismo arraigara y tuviese éxito en Venezuela.

\footnotetext{
${ }^{44}$ http://www.cne.gov.ve/resultados/

${ }^{45}$ Citamos por Gott, op. cit., p. 126.
} 
Javier Rodríguez Martínez es Profesor Titular de Sociología desde 1996. Ha publicado numerosos artículos y traducciones sobre Max Weber, además de otros sobre Cambio Social y Metodología de las Ciencias Sociales. En la actualidad está preparando los capítulos sobre Marx y Max Weber para un manual de Historia de la teoría sociológica que pronto será publicado por la editorial Síntesis. jrodriguez@poli.uned.es 